\title{
AN EVALUATION OF A PHARMACIST-LED DIABETES SERVICE IN A PUBLIC HEALTH DEPARTMENT POPULATION
}

\author{
B. DeeAnn Dugan ${ }^{1 *}$, Roger D. Lander ${ }^{1}$, Jessica Skelley ${ }^{1}$, Bryn Manzella ${ }^{2}$ \\ ${ }^{1}$ Department of Pharmacy Practice, McWhorter School of Pharmacy, Samford University, 800 Lakeshore Drive, \\ Birmingham, AL 35229 \\ ${ }^{2}$ Director of Quality Improvement, Jefferson County Department of Health, Quality Improvement and Decision \\ Support, 1400 Sixth Avenue South, Birmingham, AL 35233
}

\section{ABSTRACT}

Objectives: Diabetes affects 29.1 million Americans. The relationship between poor health literacy, lower socioeconomic status, the psychosocial barriers related to diabetes is well established. With the association between glycemic control and diabetes complications, the importance of patient education/management to improve self-efficacy and glucose control is compelling. Several studies have demonstrated the impact of pharmacist-led diabetes education/management services in self-insured employer groups; however little has been published with patients facing access, income, and health literacy challenges. Study objective: To evaluate the impact of a pharmacist-led diabetes clinic in a public health department population.

Methods: Public health department patients with diabetes and hemoglobin A1c (A1C) $\geq 9 \%$ were identified by electronic medical record query or referral. Intervention group patients were enrolled in the pharmacist-led diabetes clinic while patients of other health centers were managed by usual care. Primary endpoint was change in A1C from baseline to study end for the intervention group.

Results: Ninety-four patients, primarily African American women age of 49.5 years, were included in the study. There were no significant differences between the groups regarding baseline characteristics; although the intervention group had a higher A1C at baseline (11.3\% vs $10.8 \%)$ than the usual care group. At the end of the study, the intervention group had an A1C reduction of $2 \%(p<0.0002)$ whereas the usual care group achieved a $0.8 \%(p=0.16)$ reduction over the same time period.

Conclusions: A pharmacist-led diabetes service is effective in enabling public health department patients to significantly reduce their average blood glucose level.

\section{INTRODUCTION}

Diabetes affects 29.1 million Americans, just over 9.3\% of the U.S. population. ${ }^{[1]}$ According to the 2014 Centers for Disease Control Diabetes Fact Sheet, there are an additional 86 million people in the U.S. who have pre-diabetes; however, most of these individuals are either undiagnosed or unaware. In 2012 the total estimated costs of diabetes, direct and indirect, were $\$ 245$ billion. ${ }^{[2]}$ Of this cost, $43 \%$ was for inpatient hospital care and $18 \%$ for medications to treat diabetes complications. More significantly, it is estimated that the number of individuals with diabetes will double by 2023 , increasing cost of this disease to a staggering $\$ 430$ billion. ${ }^{[3]}$ Higher health literacy has been associated

*Corresponding author:

Email: bdugan@samford.edu

http://dx.doi.org/10.20530/IJTA 33 1-8

ISSN 2320-138X (c) 2016 with improved self-management behaviors. ${ }^{[4]}$ McCleary-Jones evaluated this association in African Americans finding a positive correlation between health literacy and both diet and exercise self-care

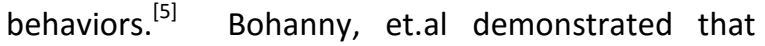
patients with higher health literacy had received diabetes education and were employed demonstrated higher self-efficacy. ${ }^{[5]}$ Lower health literacy has been associated with poor self-efficacy and poorer health outcomes. Several studies have confirmed an association between inadequate health literacy, diabetes self-management, and adverse outcomes. ${ }^{[6],[7],[8]}$ The evidence concerning the social determinants of health in patients with diabetes is equally compelling. Hill and colleagues list several reasons, such as the financial burdens associated with the disease, insufficient access to needed resources, decreased personal productivity, why low socioeconomic status is particularly problematic for those with diabetes. ${ }^{[9]}$ In an article by Forsass, et.al, it was found that among type 1 and type 2 diabetic men and women, poor or no 
Table 1: Baseline Characteristics of Patients

\begin{tabular}{|c|c|c|}
\hline & Intervention group $(n=45)$ & Usual Care group $(n=49)$ \\
\hline Age: Range, & $22-92$ & $22-73$ \\
\hline Mean ( \pm S.D.) & $49(13.1)$ & $50(12.7)$ \\
\hline Gender & $13 \mathrm{M} ; 32 \mathrm{~F}$ & $12 \mathrm{M} ; 37 \mathrm{~F}$ \\
\hline Baseline SBP (mmHg): Range, & $80-190$ & $100-190$ \\
\hline Mean ( \pm S.D.) & $134(21.8)$ & $134.8(19.6)$ \\
\hline Baseline DBP: Range, & $60-110$ & $56-106$ \\
\hline Mean ( \pm S.D.) & $86(10.6)$ & $82.4(11.7)$ \\
\hline A1C: Range & $9.0-21.7$ & $9-14.3$ \\
\hline Mean ( \pm S.D.) & $11.3(2.67)$ & $10.8(1.44)$ \\
\hline BMI: Range & $22.0-55.8$ & $19.9-55.4$ \\
\hline Mean ( \pm S.D.) & $36.5(9.3)$ & $35.7(8.9)$ \\
\hline LDL: Range & $23-257$ & $55-181$ \\
\hline Mean ( \pm S.D.) & $113.9(46.2)$ & $117.5(33.2)$ \\
\hline HDL: Range & $23-83$ & $24-108$ \\
\hline Mean ( \pm S.D.) & $49.3(14.3)$ & 46.7 (14.9) \\
\hline Triglycerides: Range & $39-699$ & $52-308$ \\
\hline Mean ( \pm S.D.) & $129.8(116.2)$ & $168.7(80.0)$ \\
\hline
\end{tabular}

Table 1 provides the baseline values for patients in both the intervention and usual care groups for age in years, systolic blood pressure (SBP) in $\mathrm{mmHg}$, diastolic blood pressure (DBP) in $\mathrm{mmHg}$, hemoglobin A1c (A1C) in \%, body mass index $(B M I)$ in $\mathrm{kg} / \mathrm{m}^{2}$, low density lipoprotein (LDL) in $\mathrm{mg} / \mathrm{dL}$, high density lipoprotein $(\mathrm{HDL}$ ) in $\mathrm{mg} / \mathrm{dL}$, and triglycerides in $\mathrm{mg} / \mathrm{dL}$.

employment, low income and limited education level were associated with greatest mortality. ${ }^{[10]}$ In addition, the association between diabetes and deprivation can be established at the level of a neighborhood. ${ }^{[11],[12] \quad F i n a l l y, ~ t h e ~ r e l a t i o n s h i p ~}$ between poor health literacy, lower socioeconomic status, the psychosocial barriers related to diabetes and poor glycemic control and diabetes related outcomes is fairly established. ${ }^{[13],[14],[15],[16]}$ Given the clear association between glycemic control and the incidence and severity of renal disease, heart disease, blindness, and non-traumatic amputation, the importance of patient education and management to improve self-efficacy, and thus glycemic control, are clear and compelling. ${ }^{[17],}$ $[18],[19],[20],[21],[22] \quad$ While glycemic control can be difficult in those without health disparities, in populations without insurance or who are the unemployed or underemployed, those of low income, and those experiencing language and cultural barriers and/or poor health literacy, the issues become substantially more difficult. ${ }^{[23],[24],[25]}$

Several studies have demonstrated the impact of pharmacist-led diabetes education and management services. $^{[26],[27],[28],[29],[30],[31]}$ When working with insured populations, particularly with self-insured employer groups, pharmacists have consistently demonstrated both improved glycemic control and better patient safety while decreasing overall medical costs. ${ }^{[32],[33],[34],[35],[36]}$ While pharmacist impact is well documented in populations outside the public health arena, little has been published related to the impact of pharmacists when working with populations facing access, income, and health literacy challenges such as those found in a public health department population. The objective of this analysis was to evaluate the effectiveness of a pharmacist-led diabetes education and management clinic in a county health department health center.

\section{MATERIALS AND METHODS}

\section{Setting}

Study patients were selected from a county public health department population in the southeast United States. The health department provides primary care services, including adult health, pediatrics, family planning, dentistry, and optometry to county residents through six strategically placed health centers located in urban areas with limited access to healthcare around the county. The county's racial composition is approximately $43 \%$ African 
Table 2: Study Parameters in Patients at the End of the Study Period

\begin{tabular}{|c|c|c|}
\hline & Intervention group $(n=45)$ & Usual Care group $(n=49)$ \\
\hline Final SBP (mmHg): Range, & $100-180$ & $106-192$ \\
\hline Mean $( \pm$ S.D.) & $132.4(17.4)$ & $133.5(22.1)$ \\
\hline Final DBP: Range, & $60-100$ & $56-110$ \\
\hline Mean ( \pm S.D.) & $83.6(9.9)$ & $82.2(11.1)$ \\
\hline A1C: Range & $6.1-15.0$ & $5.9-14.4$ \\
\hline Mean ( \pm S.D.) & $9.3(2.1)$ & $10.0(2.6)$ \\
\hline BMI: Range & $21.4-56.5$ & $18.5-57.6$ \\
\hline Mean ( \pm S.D.) & $36.9(9.1)$ & $35.7(9.3)$ \\
\hline LDL & $22-191$ & $34-198$ \\
\hline Mean ( \pm S.D.) & 105.7 (38.9) & $105.8(33.4)$ \\
\hline $\mathrm{HDL}$ & $29-79$ & $16-113$ \\
\hline Mean ( \pm S.D.) & $51.1(14.2)$ & $46.8(16.6)$ \\
\hline Triglycerides & $39-699$ & $60-509$ \\
\hline Mean ( \pm S.D.) & $127.8(39.0)$ & $175.5(112.2)$ \\
\hline
\end{tabular}

Table 2 provides the study completion values for patients in both the intervention and usual care groups for age in years, systolic blood pressure (SBP) in $\mathrm{mmHg}$, diastolic blood pressure (DBP) in $\mathrm{mmHg}$, hemoglobin A1c (A1C) in \%, body mass index (BMI) in $\mathrm{kg} / \mathrm{m}^{2}$, low density lipoprotein (LDL) in $\mathrm{mg} / \mathrm{dL}$, high density lipoprotein $(\mathrm{HDL}) \mathrm{in} \mathrm{mg} / \mathrm{dL}$, and triglycerides in $\mathrm{mg} / \mathrm{dL}$.

American, 54\% Caucasian, and 4\% Latino based on 2013 data. $^{[37]}$ The median family income is approximately $\$ 45,000 ; 15 \%$ lower than the 2012 national median. Seventeen percent of the county's population lives below poverty. ${ }^{[37]}$ The median family income in the area of the county the health department primarily serves is approximately half that of the US median family income. According to 2009 data, patients seen in the Diabetes Clinic at the health department had a mean annual income of $\$ 9,400$.

\section{Study Design:}

Eligible patients were identified using the electronic medical record, as well as by active referral of the health department's primary care provider. To be included in the study, patients had to be at least 19 years old, have either type 1 or type 2 diabetes with the most recent hemoglobin $\mathrm{A} 1 \mathrm{C}(\mathrm{A} 1 \mathrm{C})$, a blood test that correlates with a person's average blood glucose level over a three month period, $\geq 9 \%$, and having been evaluated by a health department primary care provider at least twice in the previous calendar year. Groups, control and intervention, were then assigned based on the health center attended as the Diabetes Clinic was located in only two of the four health department health centers. Patients currently being seen at the two Health Centers where the Diabetes Clinic service was available were allocated to the intervention group. Those patients who went to health centers that did not have a Diabetes Clinic service were allocated to the control group for comparison. Exclusion criteria included refusal to attend the Diabetes Clinic, change to a primary care provider outside the health department health centers, and age < 18 years. Patient recruitment began in September 2010 and continued through December 2010 with the study concluding in August 2011. This evaluation did not require IRB approval as it was a quality initiative analysis of the program. On this basis, the IRB declined review of the program.

\section{Practice Model Description:}

Patients were seen in the Diabetes Clinic at 4 to 6 week intervals. A three-visit educational protocol was used to standardize visit content although education and management activities were tailored to patient needs. The initial visit focused on signs and symptoms of diabetes, disease complications, goals of therapy, A1C and its interpretation, medications and how they work, and glucose meter education. The second visit addressed diet, exercise, foot care, and what to expect from physician visits. The third visit involved an assessment of the patient's progress, review of key concepts, and a revisiting of any concepts still not understood by the patient. At all visits, medications were reconciled, 
patients were screened for adverse drug events, self-monitored blood glucose (SMBG) logs were reviewed, and drug therapy was managed as needed; including insulin and oral medications. Patients also received follow-up phone calls during insulin titrations to verify appropriateness of therapy and to enhance patient safety. Patients who reached the desired goal $(A 1 C<7 \%)$ at the third visit were given the option to be discharged from the care of Diabetes Clinic; however, patients were encouraged to contact the Diabetes Clinic for additional appointments for any issues or if loss of control occurred. Patients still not at goal at the third visit continued to be seen by the Diabetes Clinic using a follow up visit protocol until control was achieved. During these visits, more intensive education and support were provided to patients and his/her support system. One of the criteria for patients to continue to be seen in the Diabetes Clinic was regularly scheduled primary care provider visits.

\section{Measures:}

To determine the impact of the pharmacistled Diabetes Clinic, the primary outcome measure selected was change in A1C from baseline to study end. Other measures collected included blood pressure, low density lipoproteins (LDL), high density lipoprotein (HDL), triglycerides (TG), and body mass index (BMI).
A1C was collected every three months as available over the course of the study. Other outcome measures were collected retrospectively as physicians ordered these during regularly scheduled appointments. Data on the number and type of clinical pharmacy services (CPS) provided for patients was also collected.

\section{Statistics:}

Since the study design involves a pre- and posttreatment comparison, a two-tailed paired t-test was used to analyze data from baseline to study end for the pharmacist-intervention group and usual care group. The a priori level of significance was set at $p<$ 0.05 . All patients who attended at least an initial visit to the Diabetes Clinic are included in results.

\section{RESULTS}

Table 1 depicts the baseline characteristics of the patients in the usual care and intervention groups. No statistically significant differences exist in any of these parameters. Table 2 shows the study parameter values at the end of follow up for both the intervention and usual care groups. The average length of follow up for the intervention and control groups was 347 and 335 days, respectively. Within group analysis demonstrated a significant decrease in the primary endpoint, with an $\mathrm{A} 1 \mathrm{C}$ reduction of

Figure 1: Clinical Pharmacy Services Provided for Diabetes Clinic Patients

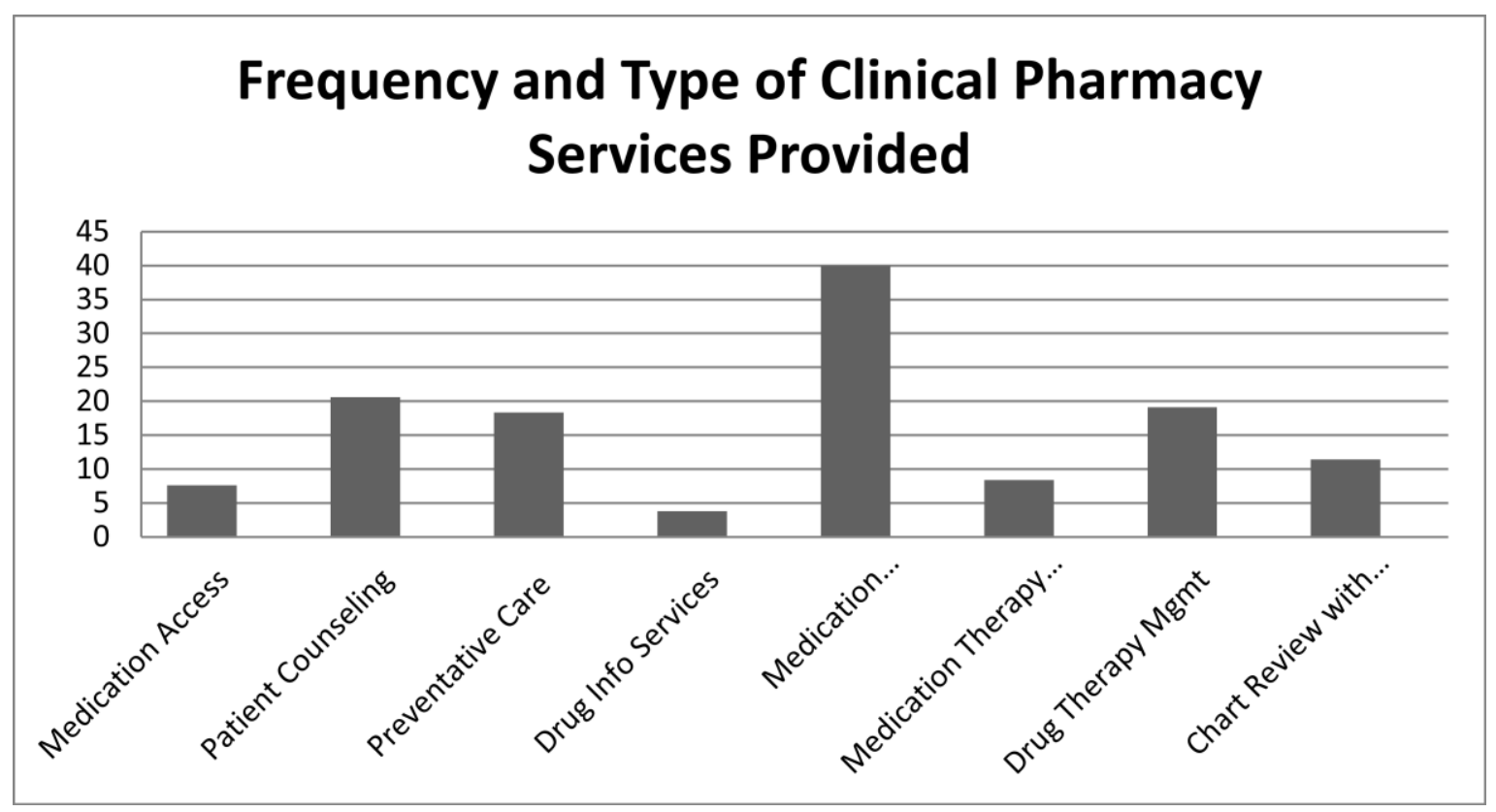

Figure 1 indicates the type and number of times each of the eight listed clinical pharmacy services was provided to patients. Mgmt= Management. 
$2 \%$ between baseline and completion in the intervention group $(p=0.0002)$. The usual care group achieved only a $0.8 \%(p=0.16)$ reduction over this same time period. Regarding secondary endpoints, while blood pressure, LDL, TG, and BMI all decreased and HDL increased, no statistically significant changes were found for either the intervention group or the usual care group.

The most common pharmacist services provided to the intervention group were medication reconciliation, patient counseling, drug therapy management, and preventive care (Figure 1).

\section{DISCUSSION}

Our results demonstrated a statistically significant A1C decrease of $2 \%$ in the pharmacist intervention group compared to a reduction of $0.8 \%$ in the usual care group. The study was unable to show a statistically significant difference on any of the secondary endpoints although all endpoints in the pharmacist intervention group decrease or increased as clinically desirable. This finding could be a function of the level of control seen at baseline for both groups. Current American Diabetes Association guidelines recommend blood pressure be less than 140/90; at the time of this study, the goal was $<130 / 80$. Patients in both groups had a baseline systolic blood pressure of $134 \mathrm{mmHg}$. Likewise, the acknowledged LDL target at the time of the study was $<100 \mathrm{mg} / \mathrm{dL}$. Baseline LDL values were 113.9 and 117.5 , intervention and usual care group, respectively. These results are similar to those of other studies of pharmacist intervention for diabetes care in non-public health settings.

Working with a primarily indigent Hispanic population at a Federally Qualified Health Center, Leal and colleagues showed an approximate $2.4 \%$ change in A1C ( $p<0.001)$ in 2004. ${ }^{[38]}$ Their group also achieved statistically significant changes in SBP (126 to $118 \mathrm{mmHG}$ ), DBP (76 to $71 \mathrm{mmHG}$ ), LDL (108 to $97 \mathrm{mg} / \mathrm{dL}$ ), triglycerides (249 to $191 \mathrm{mg} / \mathrm{dL}$ ), and TC (204 to $181 \mathrm{mg} / \mathrm{dL}$ ). Body mass index and high density lipoprotein showed no statistically significant change in this study.

In a different Community Health Center with primarily Caucasian (40\%) and Hispanic (39\%) patients with incomes at or below poverty (61\%) and thirty-three percent who were insured by Medicaid, pharmacist intervention achieved an A1C decrease of approximately $1.7 \%(p<0.05)$ as well as statistically significantly lowering SBP (130 to 126
$\mathrm{mmHG}$ ) and LDL (116 to $96 \mathrm{mg} / \mathrm{dL}$ ). ${ }^{[39]}$ Similiar to Leal's study, BMI and HDL were not significantly changed. In contrast to Leal, however, DBP also was unable to demonstrate significant change in this study.

In a controlled trial with 159 patients in a Community Health Center, again largely comprised of Caucasian (31\%) and Hispanic (58.5\%) patients, pharmacist care for diabetes patients realized a $1.4 \%$ A1C decrease compared to a $0.9 \%$ decrease in control group patients. ${ }^{[40]} \mathrm{LDL}$ was also reduced significantly (129 to $102 \mathrm{mg} / \mathrm{dL}, \mathrm{p}<0.001$ ). Of note, $88.1 \%$ of intervention group patients were uninsured while only $67.6 \%$ of control group patients were uninsured in this study.

Finally, a study of pharmacist intervention conducted in an academic general medicine clinic showed an $\mathrm{A} 1 \mathrm{C}$ reduction of $1.9 \%$ at 6 months in a population insured by Medicaid (58\%) that was primarily African American (69\%) and in whom 56\% had less than a high school education. ${ }^{[41]}$

Interestingly, data indicated that the most common pharmacy service provided was medication reconciliation, followed by patient counseling and drug therapy management. This information may provide insight into the success of the intervention program. Common adherence challenges in patients with diabetes include paying for medications and remembering doses. ${ }^{[42]}$ Factors which appear to influence adherence include a patient's understanding of the treatment regimen, the benefits of the regimen, as well as regimen costs and complexity. ${ }^{[43]}$ Pharmacist education and counseling on diabetes medications, including proper medication administration and adverse drug events, patient self-monitoring, lifestyle changes, and motivational interviewing techniques have been shown to improve adherence and, subsequently, patient outcomes. ${ }^{[44]}$ This study further supports these previous reports.

Our study has several limitations. First, while a usual care group was utilized as a control, the trial was not randomized. Usual care patients were drawn from different health centers than intervention group patients. This was done to assist in removing the pharmacy team as a confounder as the team works with providers during the adult health clinics daily. And while there is no reason to think control patients fundamentally differ from those in the intervention group, it does introduce the possibility of selection bias. Second, although 
greater A1C lowering was achieved with intervention patients, this group had a higher A1C at baseline than usual care patients. Finally, although the primary outcome measure was collected prospectively, secondary measures were gathered retrospectively.

\section{CONCLUSION}

This program analysis showed that a pharmacistled diabetes education and management service based in a public health department is effective in assisting low income, largely uninsured, primarily African American patients in statistically reducing A1C. Given the burden of diabetes within the African American population as well as the documented impact of improving diabetes education to improve self-efficacy, engaging pharmacists to assist or manage a diabetes service for populations facing socioeconomic barriers may be considered.

\section{REFERENCES}

1. [Internet]. 2016 [cited 12 May 2016]. Available from: http://1.www.cdc.gov/diabetes/pubs/statsreport14/ national-diabetes-report-web.pdf

2. Economic costs of diabetes in the U.S. in 2012. Diabetes Care 2013;36:1033-1046. Diabetes Care. 2013 May 23;36(6):1797-1797. Available from: http://dx.doi.org/10.2337/dc13-er06.

3. Bodenheimer T, Chen E, Bennett HD. Confronting The Growing Burden Of Chronic Disease: Can The U.S. Health Care Workforce Do The Job? Health Affairs. 2009 Jan 1;28(1):64-74. Available from: http://dx.doi.org/10.1377/hlthaff.28.1.64.

4. Bohanny W, Wu S-FV, Liu C-Y, Yeh S-H, Tsay S-L, Wang T-J. Health literacy, self-efficacy, and self-care behaviors in patients with type 2 diabetes mellitus. Journal of the American Association of Nurse Practitioners. 2013 Mar 4;25(9):495-502. Available from: http://dx.doi.org/10.1111/1745-7599.12017.

5. McCleary-Jones V. Health Literacy and its association with diabetes knowledge, self-Efficacy and disease self-management among african americans with diabetes mellitus. ABNF Journal. 2011 Spring; 22(2): 25-32.

6. Nath C. Literacy and Diabetes Self-Management. AJN, American Journal of Nursing. 2007 Jun;107(Supplement):43-9. Available from: http://dx.doi.org/10.1097/01.naj.0000277829.28043. 93.

7. Kim S, Love F, Quistberg DA, Shea JA. Association of Health Literacy With Self-Management Behavior in Patients With Diabetes. Diabetes Care. 2004 Nov
23;27(12):2980-2. Available from: http://dx.doi.org/10.2337/diacare.27.12.2980.

8. Tang YH, Pang SMC, Chan MF, Yeung GSP, Yeung VTF. Health literacy, complication awareness, and diabetic control in patients with type 2 diabetes mellitus. Journal of Advanced Nursing. 2008 Apr;62(1):74-83. Available from: http://dx.doi.org/10.1111/j.13652648.2007.04526.x.

9. Hill J. Understanding the Social Factors That Contribute to Diabetes: A Means to Informing Health Care and Social Policies for the Chronically III. The Permanente Journal. 2013 Apr 22;17(2):67-72. Available from: http://dx.doi.org/10.7812/tpp/12099.

10. Forssas E, Manderbacka K, Arffman M, Keskimaki I. Socio-economic predictors of mortality among diabetic people. The European Journal of Public Health. 2011 Apr 15;22(3):305-10. Available from: http://dx.doi.org/10.1093/eurpub/ckr044.

11. Schmitz N, Nitka D, Gariepy G, Malla A, Wang J, Boyer $R$, et al. Association Between Neighborhood-Level Deprivation and Disability in a Community Sample of People With Diabetes. Diabetes Care. 2009 Aug 12;32(11):1998-2004. Available from: http://dx.doi.org/10.2337/dc09-0838.

12. Ludwig J, Sanbonmatsu L, Gennetian L, Adam E, Duncan GJ, Katz LF, et al. Neighborhoods, Obesity, and Diabetes - A Randomized Social Experiment. N Engl J Med. 2011 Oct 20;365(16):1509-19. Available from: http://dx.doi.org/10.1056/nejmsa1103216.

13. Brown AF. Socioeconomic Position and Health among Persons with Diabetes Mellitus: A Conceptual Framework and Review of the Literature. Epidemiologic Reviews. 2004 Jul 1;26(1):63-77. Available from: http://dx.doi.org/10.1093/epirev/mxh002.

14. Glasgow RE, Toobert DJ, Gillette CD. Psychosocial Barriers to Diabetes Self-Management and Quality of Life. Diabetes Spectrum. 2001 Jan 1;14(1):33-41. Available from: http://dx.doi.org/10.2337/diaspect.14.1.33.

15. McEwen LN, Kim C, Karter AJ, Haan MN, Ghosh D, Lantz PM, et al. Risk Factors for Mortality Among Patients With Diabetes: The Translating Research Into Action for Diabetes (TRIAD) Study. Diabetes Care. 2007 Apr 27;30(7):1736-41. Available from: http://dx.doi.org/10.2337/dc07-0305.

16. Whiting D, Unwin N, Roglic G. Diabetes: equity and social determinants [Internet]. 1st ed. Geneva: World Health Organization; 2010 [cited 12 May 2016]. Available from: http://www.who.int/sdhconference/resources/Equity SDandPH_eng.pdf 
17. The Effect of Intensive Treatment of Diabetes on the Development and Progression of Long-Term Complications in Insulin-Dependent Diabetes Mellitus. N Engl J Med. 1993 Sep 30;329(14):977-86. Available from: http://dx.doi.org/10.1056/nejm199309303291401

18. Retinopathy and Nephropathy in Patients with Type 1 Diabetes Four Years after a Trial of Intensive Therapy. N Engl J Med. 2000 Feb 10;342(6):381-9. Available from: http://dx.doi.org/10.1056/nejm200002103420603.

19. Intensive Diabetes Treatment and Cardiovascular Disease in Patients with Type 1 Diabetes. N Engl J Med. 2005 Dec 22;353(25):2643-53. Available from: http://dx.doi.org/10.1056/nejmoa052187.

20. Holman RR, Paul SK, Bethel MA, Matthews DR, Neil HAW. 10-Year Follow-up of Intensive Glucose Control in Type 2 Diabetes. N Engl J Med. 2008 Oct 9;359(15):1577-89. Available from: http://dx.doi.org/10.1056/nejmoa0806470.

21. Intensive blood-glucose control with sulphonylureas or insulin compared with conventional treatment and risk of complications in patients with type 2 diabetes (UKPDS 33). The Lancet. 1998 Sep;352(9131):837-53. Available from: http://dx.doi.org/10.1016/s01406736(98)07019-6.

22. Effect of intensive blood-glucose control with metformin on complications in overweight patients with type 2 diabetes (UKPDS 34). The Lancet. 1998 Sep;352(9131):854-65. Available from: http://dx.doi.org/10.1016/s0140-6736(98)07037-8.

23. Ali M, McKeever Bullard K, Imperatore G, Barker L, Gregg E. Characteristics associated with poor glycemic control among adults with self-reported diagnosed diabetes--National Health and Nutrition Examination Survey, United States, 2007-2010. MMWR Supplements. 2012 June; 61(21):32-37

24. Institute of Medicine (US) Committee on Health Insurance Status and Its Consequences. America's Uninsured Crisis. 2009. Accessed May 10, 2016. Available from: http://www.ncbi.nlm.nih.gov/books/NBK214966.

25. Smedley BD, Stith AY, Nelson AR. The healthcare environment and its relation to disparities. In: Unequal treatment. Washington, D.C.: National Academy Press; 2003. [cited 2016 July 21]. p. 80-120. Available from http://www.nationalacademies.org/hmd/Reports/20 02/Unequal-Treatment-Confronting-Racial-andEthnic-Disparities-in-Health-Care.aspx.

26. Coast-Senior E. Management of patients with type 2 diabetes by pharmacists in primary care clinics. Annals of Pharmacotherapy. 1998 Jun 1;32(6):636-
41. Available from: http://dx.doi.org/10.1345/aph.17095.

27. Jaber L, Halapy H, Fernet M, Tummalapalli S, Diwakaran H. Evaluation of a pharmaceutical care model on diabetes management. The Annals of Pharmacotherapy. 1996 Mar; 30(3):238-243.

28. Machado M, Bajcar J, Guzzo GC, Einarson TR. Sensitivity of Patient Outcomes to Pharmacist Interventions. Part I: Systematic Review and MetaAnalysis in Diabetes Management. Annals of Pharmacotherapy. 2007 Aug 21;41(10):1569-82. Available from: http://dx.doi.org/10.1345/aph.1k151.

29. Cioffi ST. Glycosylated Hemoglobin, Cardiovascular, and Renal Outcomes in a Pharmacist-Managed Clinic. Annals of Pharmacotherapy. 2004 Mar 16;38(5):7715. Available from: http://dx.doi.org/10.1345/aph.1d359.

30. Johnson $\mathrm{CL}$, Nicholas $\mathrm{A}$, Divine $\mathrm{H}$, Perrier DG, Blumenschein $\mathrm{K}$, Steinke DT. Outcomes from DiabetesCARE: A pharmacist-provided diabetes management service. Journal of the American Pharmacists Association. 2008 Nov;48(6):722-30. Available from: http://dx.doi.org/10.1331/japha.2008.07133.

31. Project IMPACT: Diabetes [Internet]. APhA Foundation. [cited 16 May 2016]. Available from: http://www.aphafoundation.org/project-impactdiabetes

32. Cranor CW, Christensen DB. The Asheville Project: Short-term outcomes of a community pharmacy diabetes care program. Journal of the American Pharmacists Association. 2012 Nov;52(6):838-50. Available from: http://dx.doi.org/10.1331/japha.2012.12542.

33. Cranor CW, Bunting BA, Christensen DB. The Asheville Project: Long-Term Clinical and Economic Outcomes of a Community Pharmacy Diabetes Care Program. Journal of the American Pharmaceutical Association (1996). 2003 Mar;43(2):173-84. Available from: http://dx.doi.org/10.1331/108658003321480713.

34. Fera T, Bluml BM, Ellis WM, Schaller CW, Garrett DG. The Medication Assessment Program: Comprehensive medication assessments for persons taking multiple medications for chronic diseases. Journal of the American Pharmacists Association. 2008 Mar;48(2):181-90. Available from: http://dx.doi.org/10.1331/japha.2008.07166.

35. Fera T, Bluml BM, Ellis WM. Diabetes Ten City Challenge: Final economic and clinical results. Journal of the American Pharmacists Association. 2009 May;49(3):383-91. Available from: http://dx.doi.org/10.1331/japha.2009.09015. 
36. Garrett DG, Bluml BM. Patient Self-Management Program for Diabetes: First-Year Clinical, Humanistic, and Economic Outcomes. Journal of the American Pharmacists Association. 2005 Mar;45(2):130-7. Available from: http://dx.doi.org/10.1331/1544345053623492.

37. State and County QuickFacts [Internet]. UNITED STATES QuickFacts from the US Census Bureau. [cited 16 May 2016]. Available from: http://quickfacts.census.gov/qfd/states/01/01073.ht $\mathrm{ml}$

38. Leal S, Glover JJ, Herrier RN, Felix A. Improving Quality of Care in Diabetes Through a Comprehensive Pharmacist-Based Disease Management Program. Diabetes Care. 2004 Nov 23;27(12):2983-4. Available from: http://dx.doi.org/10.2337/diacare.27.12.2983.

39. Scott DM, Boyd ST, Stephan M, Augustine SC, Reardon TP. Outcomes of pharmacist-managed diabetes care services in a community health center. American Journal of Health-System Pharmacy. 2006 Nov 1;63(21):2116-22. Available from: http://dx.doi.org/10.2146/ajhp060040

40. Shane-McWhorter L, Oderda GM. Providing Diabetes Education and Care to Underserved Patients in a Collaborative Practice at a Utah Community Health
Center. Pharmacotherapy. 2005 Jan;25(1):96-109. Available from: http://dx.doi.org/10.1592/phco.25.1.96.55623.

41. Dent LA, Stratton TP, Cochran GA. Establishing an Onsite Pharmacy in a Community Health Center to Help Indigent Patients Access Medications and to Improve Care. Journal of the American Pharmaceutical Association (1996). 2002 May;42(3):497-507. Available from: http://dx.doi.org/10.1331/108658002763316932.

42. Odegard PS, Gray SL. Barriers to Medication Adherence in Poorly Controlled Diabetes Mellitus. The Diabetes Educator. 2008 Jul 1;34(4):692-7. Available from: http://dx.doi.org/10.1177/0145721708320558.

43. Rubin RR. Adherence to pharmacologic therapy in patients with type 2 diabetes mellitus. The American Journal of Medicine. 2005 May;118(5):27-34. Available from: http://dx.doi.org/10.1016/j.amjmed.2005.04.012.

44. Meece J. Improving Medication Adherence Among Patients With Type 2 Diabetes. Journal of Pharmacy Practice. 2013 Dec 27;27(2):187-94. Available from: http://dx.doi.org/10.1177/0897190013513803. 